\title{
Microbiological identification in Kundi, an Intermediate Moisture Meat (IMM) product
}

\section{P.O. Fakolade ${ }^{1}$, A. B. Omojola ${ }^{2}$}

${ }^{1}$ Osun State University, Ejigbo, Osun, Nigeria, ${ }^{2}$ University of Ibadan, Ibadan, Oyo, Nigeria

Email: twinsfakolade@yahoo.com

Introduction Meat and meat products are high in nutritive value and because of this they can only remain fresh for a short time before spoilage sets in, but simple preservative techniques can reduce spoilage. One such simples techniques is Intermediate Moisture Meat processing (IMM). Obanu (1981), observed that IMM are shelf stable under the tropical climate without refrigeration and may be eaten directly with or without rehydration. Ogunsola and Omojola (2008) stated that IMM is used to describe meat products that have less than $30 \%$ of moisture. Kundi is one of such IMM products that is easy to prepare. It is therefore the objective of this study to identify the microbial loads in Kundi products.

Material and methods Beef used for this study was obtained from the slaughter slab of the department of Animal Science, University of Ibadan, Oyo state, Nigeria. Semimembranous muscle from the hindquarter, weighing 2kg from 2-3years old White Fulani animals was used. Meat was trimmed of all external fats, nerves, blood vessels, excess epimysial connective tissues and deboned and wash with water. The chunks were held overnight for 24 hours at $4{ }^{0} \mathrm{C}$, cut into sizeable small portion of $70-90$ grams of $6 \mathrm{~cm}-8 \mathrm{~cm}$ wide. Kundi process involves two methods of preservations; boiling and drying. Meat samples were boiled in a pressure cooker for 30 minutes at $100^{\circ} \mathrm{C}$ and then oven dried at $170{ }^{\circ} \mathrm{C}$ for 3 hours. Microbial status was determined by isolating and identifying and characterizing the organisms according to the method described by Norris and Ribbon (1971). The organisms were identified using their colour and the shape of their colonies. The identification was carried out monthly during six month of storage. Samples were stored at room temperature on the shelf according to Sonaiya (1997) in the departmental laboratory, they were not packaged and samples gave $32.09 \%$ as the final moisture content.

Results Fungi and mold were identified; they include Aspergillus flavus, Aspergillus niger, Penicillin spp, Rhizoppus spp, Mucor spp and Fasarium spp. Most of the Fungi isolated were xerophilic, which are organisms that are capable of growth at low water activity $\left(\mathrm{a}_{\mathrm{w}}\right)$ of less than $0.83 \mathrm{a}_{\mathrm{w}}$ are well adapted to dry arid partially dry food (Pitt, 1975). Alonge (1984) screened some Fungi isolated from Kundi products for alflatoxin. No toxin was detected because all the organisms identified grow at a very low water activity e.g Asperillus flavus grows at $\mathrm{a}_{\mathrm{w}}$ of 0.75 . Leister et al (1981) reported that alflatoxin cannot be found in meat products with water activity $\mathrm{a}_{\mathrm{w}}$ below 0.83 . The dried meat in this study and that study by Alonge (1984) had $\mathrm{a}_{\mathrm{w}}$ values below 0.83 .

Table 1 Xerophilic Fungi isolated from Kundi incubated at $73^{\circ} \mathrm{C}$

\begin{tabular}{ll}
\hline \hline Microbes & Descriptions \\
\hline Aspergillus flavus & Large bright - green colonies with yellowish centuries, Sterigmata, Uniserate \\
Asperillus niger & Black radiating colonies with large conidia heads was seen \\
Penicillum spp & Had distinct blue - green white at first ten coloured after conidial matures \\
Rhizoppus spp & The fungus quickly filling the culture plate with a dense colony aerial mycelium at first white and \\
& later becomes grey \\
Mucor spp & Fast growing fungus filling a Petri plate with colony aerial mycelium at first white and later \\
becoming dark grey brown or yellow & \\
Fusarium spp & This fungus was at first white in colony or woody then it frequently becomes pale in the hyphae or \\
& in the substrate
\end{tabular}

Conclusion Results shows that at 6 months of storage, microbiological organisms identified were fungi and molds, and since Kundi is a ready to cook meat product, and that the organisms identified are not toxigenic but xerophilic, thus Kundi is a good Intermediate Moisture Meat.

Acknowledgements Author gratefully acknowledges funding from P.G. School University of Ibadan. Nigeria

\section{References}

Alonge. 1984. Smoke preservation of meats in Nigeria: Quality and public health aspects Ph.D Thesis University of Ibadan, Ibadan.

Ogunsola O. O and Omojola A.B. 2008. Nutritional evaluation of a Dehydrated Shredded Meat Product, (Danbunama). Paskistan, Journal of Nutrition 7, $554-556$. 